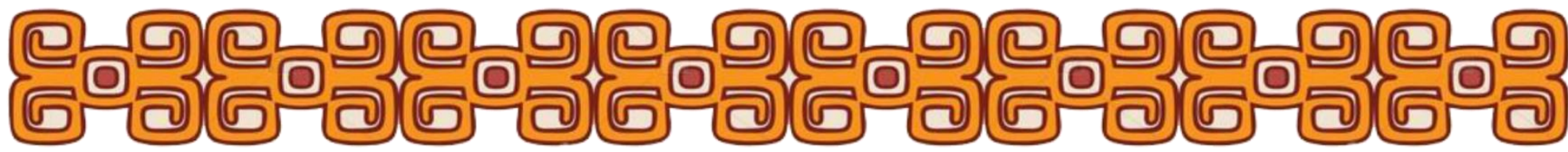

\title{
O ALUNO É O "LOBO DO HOMEM"? O BULLYING COMO REPRODUÇÃO DAS RELAÇÕES DE DOMINAÇÃO SOCIAL NA ESCOLA
}

\author{
Luciana Martins de Souza \\ Guilherme Gitahy de Figueiredo
}

\section{RESUMO}

O presente artigo traz os resultados da pesquisa sobre o bullying realizada em uma escola pública municipal de Tefé (AM), e que utiliza teorias sobre estigma e rotulação. Foi possivel constatar um número elevado de estudantes que estão sendo rotulados e agredidos no ambiente escolar, o prejuízo que isto causa no interesse pelos estudos, e as maneiras pelas quais essas formas de violência estão reproduzindo relações de dominação que existem fora da escola.

\section{PALAVRAS-CHAVE}

Bullying; Estigma; Rotulação; Escola.

\section{INTRODUÇÃO}

Desde 1970, o tema bullying vem ganhando espaço na mídia e nos estudos sobre a violência escolar, e tem tido o importante mérito de chamar a atenção para diversos tipos de violência. Por outro lado, os estudiosos do bullying tendem a ignorar as hierarquias sociais e as violências de classe, raça, gênero e geração, ao enfatizar a psicologia individual como fonte privilegiada para as explicações sobre a violência, suas origens e consequências. Um bom exemplo é obra de Moz e Zawadski (2007), para quem o bullying pode ocorrer em praticamente qualquer contexto no qual as pessoas interajam, seja o bairro, escola, faculdade, universidade, trabalho ou no ambiente familiar. Está presente tanto em escolas privadas quanto nas públicas, religiosas, internatos, escolas técnicas, faculdades e universidades, em escolas em que os alunos têm boas notas nos exames nacionais, e nas escolas em que as notas são baixas. Em comunidades com "famílias estruturadas" e com os pais presentes, e em famílias tidas como "desestruturadas" e com situação econômica difícil. Se este enfoque parece, a princípio, livrar os grupos sociais marginalizados da rotulação em que são frequentemente associados à origem da violência, por outro lado dilui a possibilidade de se estudar as conexões entre a violência na escola e as relações de dominação social étnica, de classe, gênero, geração, estética, etc..

$\mathrm{Na}$ pesquisa aqui apresentada, o interesse nas formas de violência atualmente vistas como bullying está relacionado à preocupação com as suas consequências para a educação escolar. Segundo Sibilia (2012, p.154), a repercussão recente do tema se deve à perda de eficácia da organização disciplinar nas escolas:

As crianças e os jovens de hoje se sentem bem mais aterrorizados com a possibilidade de sofrer acossamento e ser publicamente desmoralizados, do que com a ideia de sofrerem advertências ou suspensões pelas autoridades institucionais por seu mau comportamento (SIBILIA, 2012, p.154).

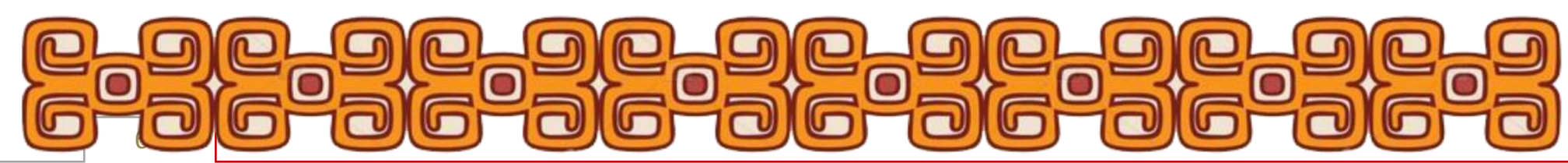




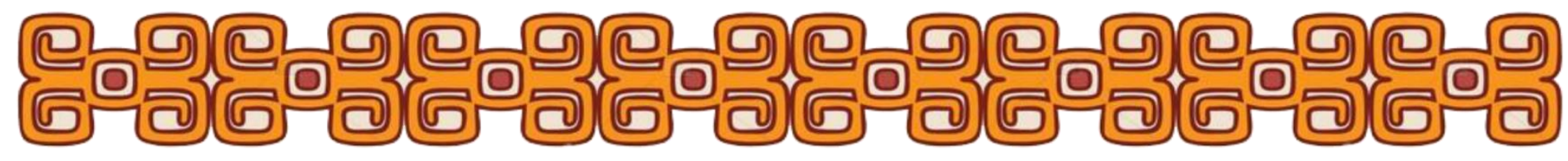

Com a disseminação de novas tecnologias e a impossibilidade de isolar as crianças e adolescentes do crescente fluxo de informações e interações à distância, as estruturas disciplinares estariam dando lugar ao consumismo e à competição, enquanto fontes da violência sofrida pelas crianças. Talvez não seja por acaso, que a violência tenha se tornado um "problema" ou "patologia" para a sociedade apenas quando começou a deixar de ser um monopólio das instituições oficiais. Esta era considerada legítima e, quando as instituições perderam o seu controle, passou a ser vista como uma ameaça oriunda de indivíduos portadores de um tipo de conduta anômala.

Seja qual for a explicação para a violência chamada bullying, o tema trouxe à tona narrativas reveladoras em que as vítimas geralmente sofrem caladas, o que acaba por resultar em isolamento, depressão, suicídio e homicídio. O dano para a educação pode chegar a extremos como, por exemplo, o caso do rapaz brasileiro de 23 anos que matou uma dezena de alunos na escola em que havia concluído os seus estudos no Rio de Janeiro. É da angústia vivenciada por milhares de crianças e adolescentes em idade escolar diante dessas novas formas de violência, e da preocupação com os danos que causam à educação, que nasceu esta pesquisa.

O estudo bibliográfico começou em 2014 abordando, sobretudo, obras relacionadas com as teorias do bullying, estigma e rotulação, em sua maioria indicadas pelo orientador. Na época a pesquisadora estava atuando através do PIBID na Escola Municipal Professor Alfredo (nome fictício), então escolheu a mesma para realizar a pesquisa. Em 2015 ela ainda era exploratória, mas começou a ganhar corpo quando foi aprovada como projeto de iniciação científica do PAIC 2015/2016. Depois ela teve continuidade como TCC do curso de Pedagogia, defendido em 2018. Os resultados aqui apresentados possuem análises feitas a quatro mãos, contando com a coautoria do orientador.

O método adotado foi a observação participante, em que o pesquisador levanta os dados "através de sua participação na vida cotidiana do grupo ou organização que estuda, (...) observa as pessoas para ver como se comportam, conversa para descobrir suas interpretações" (BECKER, 1997, p.46). Como afirma o autor, este método permite combinar diferentes tipos de técnicas, tirando assim o máximo de vantagem da longa permanência em campo. A observação participante com registro sistemático em diário começou no mês de outubro de 2015 e terminou em junho de 2016. As observações eram feitas em dois ou três dias por semana, em uma turma do $3^{\circ}$, uma do $4^{\circ}$ e duas do $5^{\circ}$ ano, no horário das 13:0oh às 17:0oh. Geralmente a pesquisadora sentava-se na última carteira da última fileira, e anotava as observações e conversas informais.

Para completar a observação, foram realizadas entrevistas gravadas com 10 alunos em uma sala de Atendimento Educacional Especializado (AEE), que foi cedida pela Direção da escola. Alguns alunos demonstraram tranquilidade ao falar do assunto, mas houve também aqueles que ficaram muito apreensivos, olhando para a parede ou o chão, e ainda outros que se mostraram sensíveis ao relatar agressões que estavam sofrendo. Durante as entrevistas, a principal dificuldade foi com o espaço cedido pela escola, pois o mesmo era dividido com os alunos do AEE que ficavam estudando ao lado, anulando a privacidade. Em alguns casos foi preciso pausar as

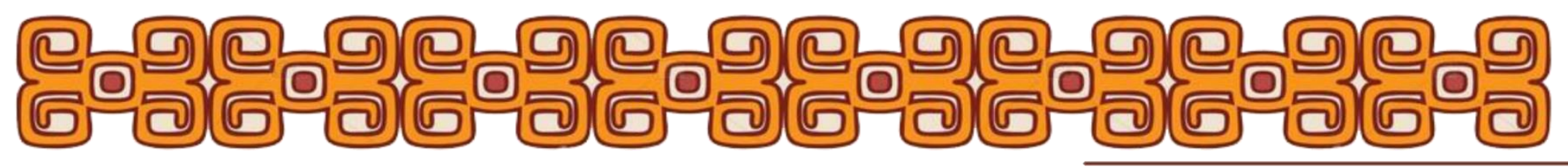




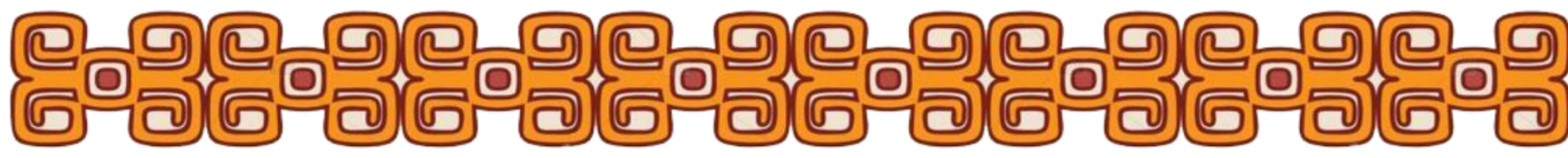

bully como sendo um "outro", desprovido da capacidade de se transformar a partir de si mesmo e em diálogo com os demais. Trata-se de alguém rotulável como bully, e que será objeto de uma necessária intervenção vertical. É, portanto, um objeto que precisa ser descrito, classificado, monitorado e controlado. Como vimos acima, trata-se da maior parte das crianças e adolescentes pesquisados.

Uma dificuldade para trazer ao estudo do bullying as teorias sociológicas e históricas é que elas são, frequentemente, de uma escala e grau de abstração que dificilmente se aproximam da experiência vivida por crianças e adolescentes dentro das escolas. Uma alternativa teórica viável, que vem sendo utilizada tanto na sociologia quanto na antropologia urbana, são os conceitos de "estigma" e "rotulação". Não falta sensibilidade a Moz e Zawadski (2007, p. 22) para essa dimensão no seu estudo, já que afirmam sobre a violência estudada por elas que: "as crianças são classificadas e confinadas em subgrupos ou panelinhas nas escolas e nos bairros, segundo sua aparência, interesse ou comportamento". Poderia haver uma relação entre o bullying e a imposição de regras sociais, já que as crianças "vivem com medo de não cumprir as regras não-ditas do pertencimento". Os desviantes seriam, então, rotulados de "os esquisitos", "os estranhos", "os rejeitados", "os retardados", "os ninguém", "os bichinhas", etc..

Segundo Goffman (2012), o estudo do "estigma" não poderia levar à identificação de grupos desviantes, pois uma mesma pessoa pode em um momento fazer o papel de "estigmatizado" e, em outro, passar ao papel de "normal". Além disso, a estigmatização também não pode ser delimitada em função dos atributos que estariam sendo depreciados, pois um mesmo atributo pode ser considerado um estigma em uma situação e, em outra, ser valorizado. A estigmatização é um "processo social de dois papéis no qual cada indivíduo participa de ambos, pelo menos em algumas conexões e em algumas fases da vida" (Goffman, 2012, p. 148), e a grande preocupação do autor é descrever a linguagem comum desse processo, que poderia ser encontrada nas mais variadas situações concretas. A busca de uma espécie de gramática da estigmatização acaba levando o autor a adotar uma teoria estática das normas sociais e das relações de poder: "uma condição necessária para a vida social é que todos os participantes compartilhem um único conjunto de expectativas normativas" (GOFFMAN, 2012, p. 138).

Por exemplo, num sentido importante, há só um tipo de homem que não tem nada do que se envergonhar: um homem jovem, casado, pai de família, branco, urbano, do Norte, heterossexual, protestante, de educação universitária, bem empregado, de bom aspecto, bom peso, boa altura e com um sucesso recente nos esportes. Todo homem americano tende a encarar o mundo sob essa perspectiva, constituindo-se isso, num certo sentido, em que se pode falar de um sistema de valores comuns na América. Qualquer homem que não consegue preencher um desses requisitos ver-se-á, provavelmente - pelo menos em alguns momentos como indigno, incompleto e inferior; em alguns momentos, provavelmente, ele se encobrirá e em outros é possível que perceba que está sendo apologético e agressivo quanto a aspectos conhecidos de si próprio que sabe serem, provavelmente, considerados indesejáveis (GOFFMAN, 2012, p .139).

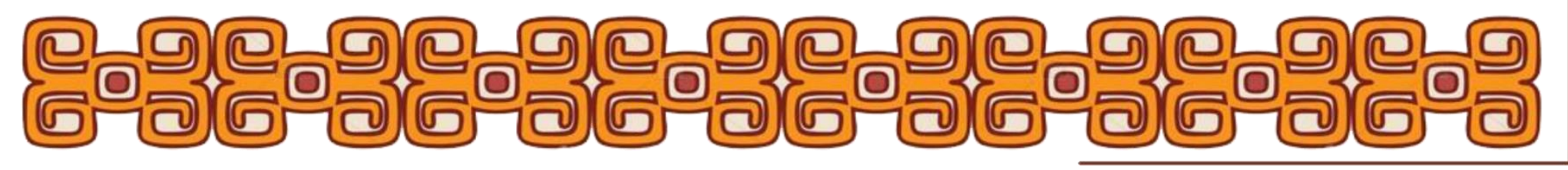




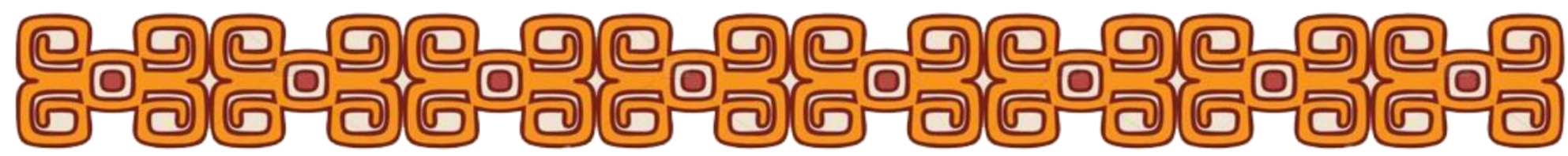

É com esta teoria microssociológica que vamos analisar os primeiros resultados da pesquisa. Depois, nas considerações finais, colocaremos os resultados numa perspectiva histórica e pedagógica auxiliados pelas teorias de Paulo Freire (2005).

\section{Os processos de rotulação e violência na Escola Municipal Professor Alfredo}

O questionário aplicado a 93 alunos foi útil para se ter uma primeira aproximação analítica sobre a incidência dos processos de rotulação e violência na escola, bem como das suas relações com o desempenho escolar. O questionário foi feito usando-se a palavra bullying, por ser este já um termo do senso comum, mas com a preocupação em levantar o que é que as crianças entendem quando empregam a palavra. Foram selecionadas setes perguntas abertas, todas de fácil compreensão, pois muitos alunos apresentavam dificuldade para ler textos grandes. Três dessas perguntas serão analisadas aqui: "o que é bullying pra você?", "você já sofreu bullying na escola?" e "você acredita que o bullying é um dos motivos para o aluno perder o interesse pela escola?". A primeira pergunta, por ser aberta, tornou possivel uma análise dos tipos de significado que os alunos atribuem à palavra bullying. As categorias especificadas abaixo foram elaboradas pela pesquisadora para classificar e quantificar as respostas, depois da aplicação do questionário.

Fonte: arquivo pessoal

\begin{tabular}{|l|l|}
\hline \multicolumn{2}{|c|}{ Tabela 1: O que é bullying pra você? } \\
\hline Agressão verbal & $38,7 \%$ \\
\hline Apelidos pejorativos & $30,1 \%$ \\
\hline Agressão física & $22,5 \%$ \\
\hline Não responderam & $8,6 \%$ \\
\hline Total de alunos que responderam o questionário & 93 \\
\hline
\end{tabular}

Dos 93 alunos que responderam o questionário, 38,7\% acreditavam ser uma agressão verbal, 30,1\% afirmaram que são os apelidos feios que os alunos colocam nos outros, $22,5 \%$ associaram o bullying a agressões físicas, enquanto $8,6 \%$ não responderam. Nesta primeira aproximação vemos que os processos de rotulação têm efetivamente um papel importante em meios às diversas formas de violência percebidas pelos alunos, mas ainda ficamos sem saber de que maneira a rotulação se relaciona com as demais agressões verbais e físicas.

Fonte: arquivo pessoal

\begin{tabular}{|l|l|}
\hline \multicolumn{2}{|c|}{ Tabela 2: Você já sofreu bullying na escola? } \\
\hline Sim & $52,6 \%$ \\
\hline Não & $40,8 \%$ \\
\hline Não responderam & $6,4 \%$ \\
\hline Total de alunos que responderam o questionário & 93 \\
\hline
\end{tabular}

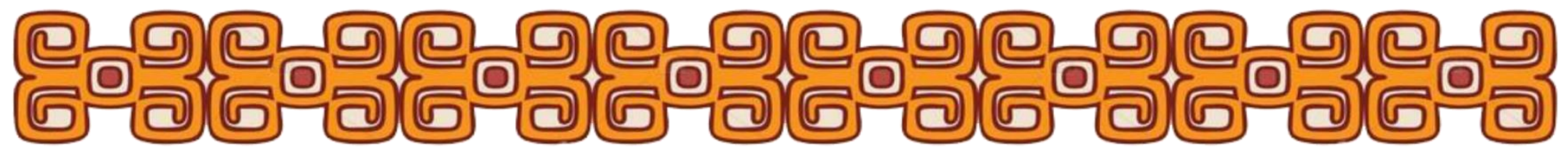




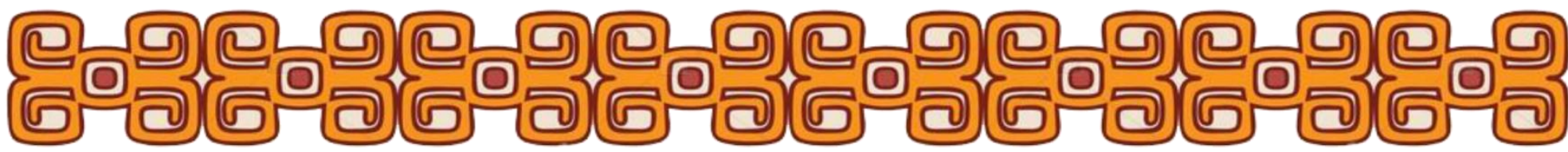

Entre os alunos deste levantamento, 52,6\% afirmaram ter sofrido bullying, $40,8 \%$ disse que não e $6,4 \%$ não respondeu à pergunta. As respostas mostram que aquelas formas de violência percebidas pelos alunos na pergunta anterior são, efetivamente, vividas por mais da metade deles no dia a dia da escola. A proporção de vítimas pode ser ainda maior, se considerarmos que pode haver alunos que sofreram violências que não se encaixam em suas próprias definições de bullying. Por exemplo: um aluno que acredita ser o bullying uma violência física pode ter sofrido agressão verbal, e por isso respondeu negativamente. A grande proporção de casos registrados pelos alunos é análoga às estatísticas apresentadas por Moz e Zawadski (2007) e à constatação de Goffman (2012) de que, diante das regras dominantes, a maior parte das pessoas em uma sociedade acaba uma hora ou outra sofrendo processos de estigmatização. Mas, afinal, qual é o papel da rotulação em meio a essas diversas formas de violência que os alunos chamam de bullying? Antes de tentar encontrar uma resposta, vejamos os efeitos da violência sobre o rendimento escolar:

Fonte: arquivo pessoal

\begin{tabular}{|l|l|}
\hline $\begin{array}{l}\text { Tabela 3: Você acredita que o bullying é um dos motivos para o aluno perder o } \\
\text { interesse na escola? }\end{array}$ \\
\hline Sim & $49,4 \%$ \\
\hline Não & $38,7 \%$ \\
\hline Não responderam & $11,8 \%$ \\
\hline Total de alunos que responderam o questionário & 93 \\
\hline
\end{tabular}

Dos 93 alunos, 49,4\% afirmaram que o bullying é um motivo para o aluno perder o interesse pela escola, enquanto $38,7 \%$ negam e $11,8 \%$ não responderam. É importante notar que a proporção de estudantes que afirmaram ter sofrido bullying $(52,6 \%)$ é quase igual à dos que relacionam ele com o desinteresse no estudo $(49,4 \%)$. Uma hipótese para explicar esta relação é que apenas as crianças e adolescentes que sofrem o bullying conhecem as suas consequências, respondendo afirmativamente para a pergunta. Para checar essa hipótese, verificamos quantos desses alunos responderam afirmativamente ou negaram o prejuízo ao interesse na escola:

Fonte: arquivo pessoal

Tabela 4: Proporção de alunos que afirmam que o bullying faz cair o interesse na escola entre aqueles que responderam já ter sofrido este tipo de violência:

Perde o interesse

Não perde $69,39 \%$ $30,60 \%$

Dos alunos que responderam ter sofrido bullying ou que estavam sofrendo na época do levantamento, 69,39\% afirmou que essa violência influencia de forma negativa em sua trajetória na escola. Por outro lado, 30,60\% responderam negativamente, talvez por se referirem a formas menos agressivas de violência ou por reunirem mais condições para se defenderem das agressões. Seja como for, a parcela que se sente prejudicada nos estudos é muito alta.

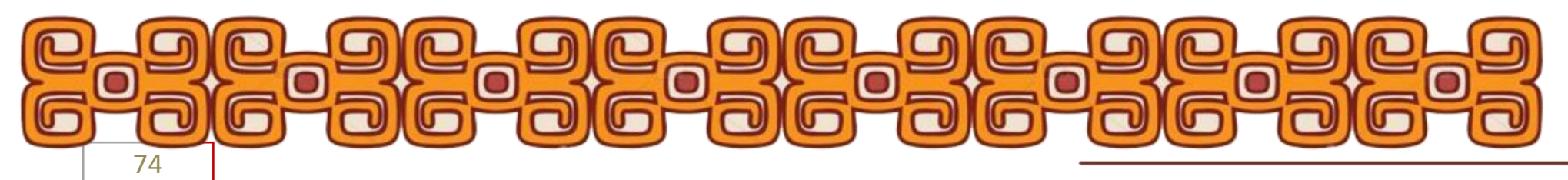




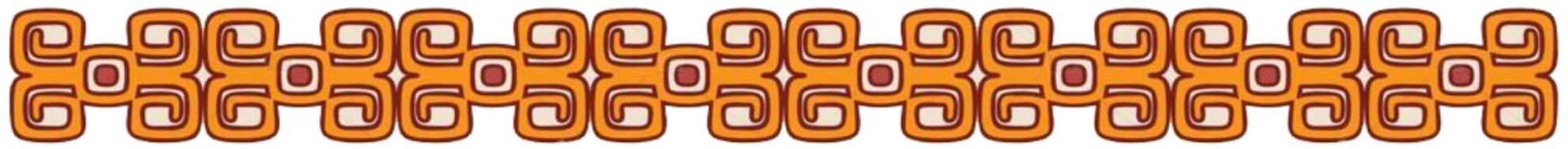

Vejamos agora os resultados da observação. No primeiro dia da aplicação desta técnica a pesquisadora ficou no $3^{\circ}$ ano e, em uma das várias conversas que teve com o professor, este informou que aquela turma era vista como "problemática": "esses alunos passaram para $03^{\circ}$ ano com muitos problemas na leitura, escrita e estão sempre assim agitados. Se deixar, eles passam a aula toda bagunçando. Tem alguns que a gente vê que eles querem alguma coisa, o resto só quer saber de brincar" (notas de campo, 28/10/2016). Afirmou ainda que ele foi escolhido para ficar com aquela turma porque já havia realizado bons trabalhos com outras, o que indica que a sua forma de lidar com uma turma "problemática" corresponde ao modelo aceito na instituição. Durante os dois meses em que a pesquisadora acompanhou esta turma, ela parecia ser realmente bem agitada. Os alunos gostavam de ficar um na cadeira do outro conversando, provavelmente porque a sala era muito apertada: como a sala era compartilhada por duas turmas, alguns alunos tinham que dividir a mesma mesa, estimulando a conversa. Alguns estudantes falavam de forma agressiva com colegas menores, enquanto outros ficavam no canto da sala, em suas cadeiras, e a pesquisadora quase não os ouvia falar. Quando o professor estava presente na sala, os alunos procuravam ficar o mais quietos possível. Se eram pegos fazendo algo que não agradava o professor, o mesmo falava de forma firme e em voz alta, porque segundo ele só assim seria respeitado.

Essas primeiras observações mostram que a rotulação e a agressividade não têm, necessariamente, origem nos alunos. As péssimas condições de estudo e trabalho contribuem para tornar os estudantes mais agitados e, após serem rotulados como "problema", passam a ser tratados com mais agressividade pela própria instituição. A agressividade observada entre os alunos parece reproduzir essa mesma lógica: enquanto a instituição se impõem com um tom mais assertivo, as crianças maiores seguem o exemplo, e fazem o mesmo com as menores. Em meio a este ambiente pouco acolhedor, outros alunos se retraem pelos cantos.

Apesar da sala ser a maior da escola, no $4^{\circ}$ ano os alunos continuavam juntando as mesas para facilitar a conversa. Muitas vezes o professor, depois de reclamar muito do barulho, separava as mesas. Os alunos gostavam de beliscar o colega com uma liga, ou jogar bolinha de papel uns nos outros. O professor reagia explicando que aquele comportamento não era adequado. Em conversa com a pesquisadora, relatou que não é fácil trabalhar com aquela turma: "quando eles estão demais eu mando para a pedagoga, ou aviso que no dia seguinte só entram com os pais" (notas de campo, 15/04/2016). Afirmou ainda que estava estudando para passar em um concurso, pois desejava trabalhar em outra área. As reações deste professor confirmam a teoria de Sibilia (2012), de que está cada vez mais difícil fazer funcionar os mecanismos disciplinares das escolas. Quando as regras autoritárias já não são mais tão facilmente aceitas pelos alunos, e ainda não existem outros mecanismos de participação na escola, o que se pode observar é que as tensões tendem a aumentar, as relações se tornam mais agressivas e desgastantes, e até o professor acaba por perder o interesse na escola.

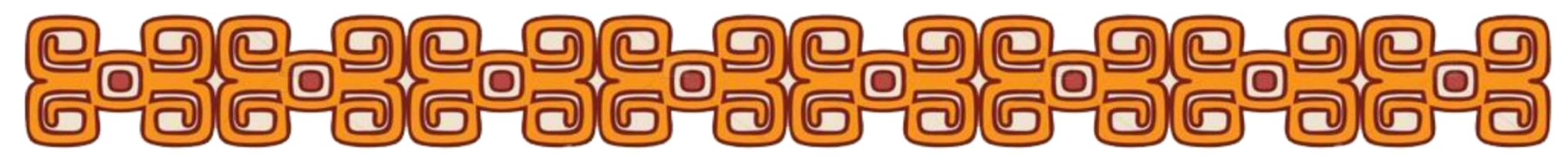




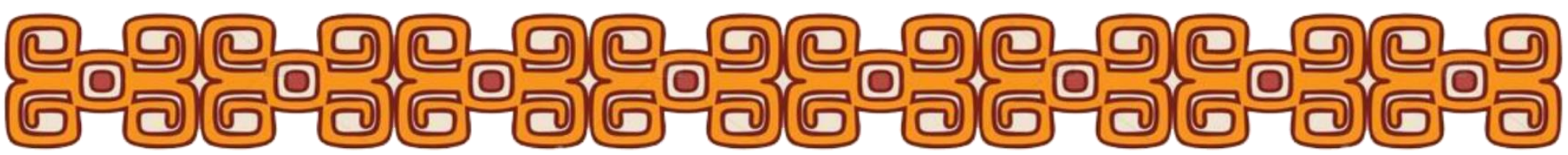

Este relato deixa mais claro como são as ligações entre as várias formas de violência detectadas no questionário e nas observações. $O$ aluno acima foi rotulado de "gay" e passou a sofrer violência física e verbal, pois alguns alunos não aceitam que um menino seja mais gentil, ou se relacione melhor com as meninas do que com os meninos. A relação de poder entre gêneros foi reproduzida dentro da escola e, quando se tornou violenta, os mecanismos disciplinares mostraram-se inoperantes. A rotulação foi o elo condutor da reprodução da violência da dominação de gênero dentro da escola, produzindo a violência verbal, a violência física, e o baixo rendimento escolar. A reação do entrevistado mostra que, para ele, as únicas alternativas para lidar com a dominação de gênero é agredir o colega ou pedir a intervenção de pais, professores e administradores da escola. A reação do pai e dos profissionais indica que, do ponto de vista deles, surgiram evidências de que o "problema" está entre os alunos, desviando a atenção das origens sociais e institucionais que precisariam ser objeto da análise pedagógica. A forma do pai de lidar com a situação é mudar o filho de escola, provavelmente buscando afastá-lo do colega ou esperando encontrar medidas disciplinares efetivas em outra escola. Os profissionais da escola, por sua vez, reagem buscando punir alunos que identificam como "culpados" por brigas envolvendo violência física.

\begin{abstract}
Sofro bullying na escola desde o ano passado. Me apelidam, me chamam de feia, me chutam. Quando eu estava escrevendo eles vinham e falavam que eu era puta, o J. era o que mais fazia isso. Eu falava para o professor, e ele levava eles para a Diretoria, falava para eles que se não parassem iria chamar meus pais. Quando iam para a Direção não melhoravam. Eu pedia para mamãe me tirar e me colocar em outra escola. Eu não tinha mais vontade de ir para a escola, porque eu não aguentava mais eles ficarem me xingando. Eu ficava com medo porque às vezes me ameaçavam, minha colega falava que ia me pegar na saída (entrevista com uma aluna do $5^{\circ}$, 09/06/2016).
\end{abstract}

A aluna sofria violência desde $04^{\circ}$ ano, e tinha dificuldade em se relacionar com as meninas de sua sala pois era rotulada por pintar o cabelo de vermelho, usar batom escuro e ter tatuagem. Durante a entrevista, ficou emocionada ao falar que seus colegas xingavam sua mãe. Ela não aguentava mais o que eles estavam fazendo. A aluna andava sempre com a mesma menina, que também sofria discriminação porque dançava hip hop. Durante os meses em que a pesquisadora ficou em sua sala, ela sentava no canto e pouco se ouvia sua voz durante as aulas. De forma análoga ao estudante acima, esta moça e sua amiga eram reprimidas ao desafiar o estereótipo machista da menina imaginada como princesa submissa. Talvez porque o machismo contempla o 'instinto de proteção' nos homens diante de garotas, enquanto o menino precisava se virar sozinho, ela contou com a ajuda de um professor. Porém, esta se mostrou ineficaz.

Já sofri várias vezes bullying aqui na escola, porque falam do jeito que eu sou, do meu jeito, do meu corpo, e agora eu pintei o meu cabelo e aí ficam falando. Aqui na escola a gente tá pra aprender né, só que o que mais acontece aqui é isso: ficam chamando nome dentro da sala, desrespeitando o professor, maltratando os colegas, aí fica uma criança violenta (entrevista com uma aluna do $5^{\circ}$ ano, 14/07/2016).

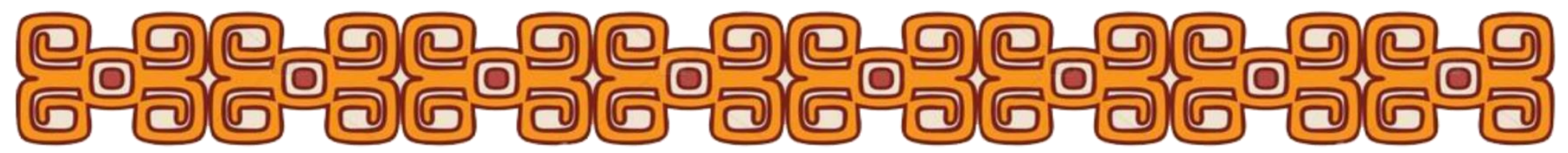




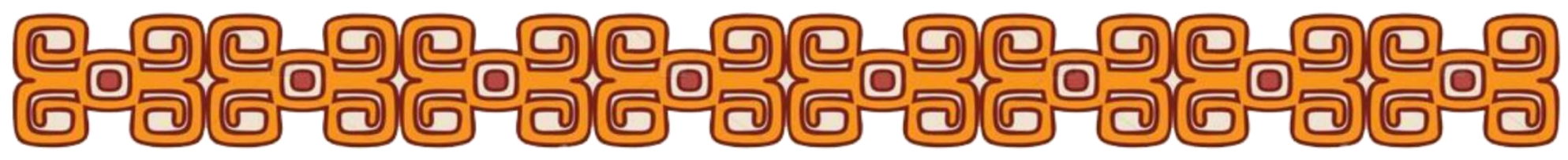

\section{CONSIDERAÇÕES FINAIS}

Durante os meses de observação participante foram registrados vários momentos de desentendimento entre os alunos e entre eles e os professores. $O$ fio condutor da violência foram rotulações que representam as relações de dominação na sociedade como: "baleia", "feio", "escravo", "cabelo de índio", "seu pobre", "magrelo", "gordo", "seu negro", etc.. A rotulação gerou outras formas de violência verbal e física: empurrões no corredor, murro, mordida no pescoço, chute e até gravata no banheiro masculino. Por fim, a violência era coroada pela violência simbólica da escola ao rotular e punir os seus alunos, e a sua exclusão direta ou indireta através de expulsões e desistências.

Nas entrevistas, alguns alunos demonstraram bastante tristeza ao falar das violências que sofriam na escola. Mesmo com a falta de privacidade na sala em que foram entrevistados, alguns acabaram desabafando e revelaram ressentimento pelo que consideram ser uma falta de apoio mais efetivo de professores e da administração. Por outro lado, nas mesmas entrevistas e também nas observações pudemos notar que os alunos frequentemente acionam pais e profissionais da escola, e que não faltaram medidas para identificar e punir os "culpados". Mesmo assim a violência se agravou e, diante disso, alguns acreditavam que a única solução era a violência como autodefesa, e acabavam também sendo punidos. Muitos terminavam sendo expulsos ou desistindo de estudar. A forma como todos os atores da escola alunos, pais, professores e gestores - lidam com a violência indica que partilham de um mesmo senso comum: a violência tem origem nos próprios alunos, e a única forma de se lidar com ela é acionando os mecanismos disciplinares.

A relação entre a violência e a queda no desempenho escolar ficou evidente. Diante de números tão altos de alunos que já sofreram bullying $(52,6 \%)$ e, entre estes, daqueles que se consideram prejudicados no estudo por sofrer esta violência $(69,39 \%)$, chega a ser estranho que apenas alguns alunos passem anos sem aprender a ler. Diante da comunidade escolar, a dificuldade de aprendizagem acaba reforçando ainda mais a rotulação dos alunos como "problema", enquanto os próprios alunos vão ficando acuados, tímidos, com medo, agressivos, desinteressados, com baixa autoestima e vendo a si próprios ou o colega ao lado como sendo o "problema". Uma hipótese forte é que isso reforça ainda mais a tendência dos alunos recorrerem à violência direta como autoafirmação ou autodefesa, da comunidade escolar acionar mecanismos disciplinares quando a tensão explode, e de alunos, pais e profissionais desistirem (ou serem expulsos) da escola quando não suportam mais essas relações. Tudo parece conspirar para confirmar o senso comum análogo à filosofia de Tomas Hobbes: aluno é um homem em "estado de natureza", e por isso é um "lobo" que precisa renunciar à sua liberdade para que uma intervenção vertical da família ou da escola traga a paz. No entanto, o que esta pesquisa revela é que a intervenção vertical não está resolvendo, chegando até a piorar as tensões, a violência e o rendimento escolar. Sibilia (2012) afirma que isso ocorre porque o acesso às novas tecnologias e formas de comunicação solapa entre os alunos as autoridades tradicionais, mas não chega a indicar alternativas para substituir os mecanismos disciplinares.

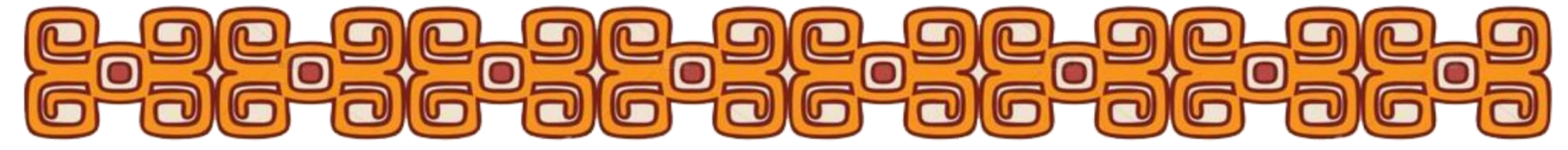




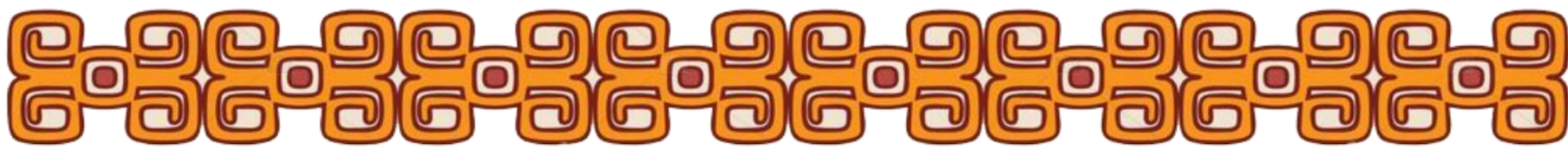

A pesquisa aqui apresentada indica que a violência não está diminuindo porque as suas principais origens - as relações de dominação social reproduzidas dentro da escola - não estão sendo transformadas em objeto de análise pedagógica, 0 que seria uma condição preliminar para que professores pesquisadores pudessem formular novos métodos educativos para envolver os estudantes em processos dialógicos de reflexão e transformação para a democratização da sociedade. Como afirma Freire (2005), a origem da violência na sociedade está em suas formas de dominação, e todas elas têm algo em comum: transformam o ser humano em "objeto" e assim produzem a sua desumanização. Não é possível, portanto, combater a violência com teorias (como as do "bullying" ou as dos "alunos problema") e práticas (como a violência direta ou os mecanismos disciplinares) em que os estudantes continuam sendo tratados como "objeto" de processos de rotulação, violência e punição disciplinar. Para romper o círculo vicioso é necessário, acima de tudo, reconhecer o estudante como sujeito e envolvê-lo em processos pedagógicos de transformação das relações de dominação. Só assim ele poderá desenvolver formas alternativas de autoafirmação e autodefesa, em que não precise mais se valer da violência ou da intervenção disciplinar.

Não se pode esperar, porém, que os atuais profissionais e famílias possam formular essas alternativas sem o necessário respaldo das universidades e das políticas públicas governamentais. No caso da Universidade do Estado do Amazonas em Tefé, por exemplo, nem mesmo o curso de pedagogia tem uma disciplina voltada para o estudo das relações de dominação de gênero, cuja presença foi marcante nessa pesquisa. Na maior parte dos cursos - e são quase todos licenciaturas - não são valorizadas as disciplinas de sociologia, antropologia e ciência política, essenciais para o estudo das relações de dominação e da emancipação dos sujeitos. Um indicador importante desta lacuna, é que a universidade não considera importante contratar professores formados nessas áreas para ministrar as poucas disciplinas existentes, de modo que frequentemente pedagogos ou historiadores fazem este trabalho. Somado a isso, a universidade ainda não parece estar dando condições suficientes para que a maioria dos futuros professores se tornem profissionais engajados em atividades de pesquisa e extensão, criando condições para as escolas buscarem suas próprias soluções ao lado de pais e estudantes. Editais e bolsas disponíveis para que os professores das escolas se engajem em atividades de pesquisa e extensão já existem nas esferas estadual e federal, mas estão sendo progressivamente cortadas.

Um ponto importante para se buscar alternativas é que sejam pesquisados aqueles processos existentes na escola, e que já são o início da construção dessas alternativas. Afinal, novas propostas para a formação de professores e de políticas públicas precisam sempre partir do reconhecimento dos atores da escola enquanto sujeitos que são não apenas capazes de iniciar a criação das alternativas, como provavelmente já o estão fazendo. Um exemplo disso é que quando surgiam situações de violência na escola foi possível observar que, enquanto a maior parte dos professores apenas mandavam os alunos para a Diretoria, um professor tentava primeiro conversar com eles. Como ele fazia? Qual era o resultado? Será que podemos encontrar outras experiências alternativas à violência e à intervenção disciplinar nas

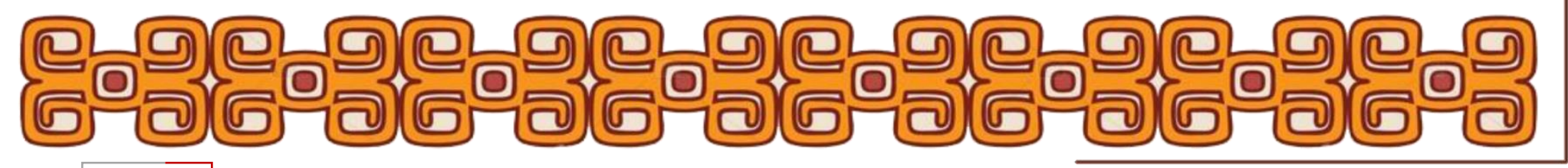




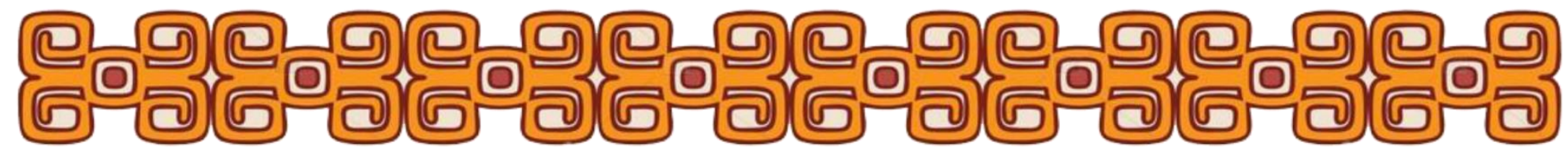

iniciativas formais e informais de alunos, professores e gestores? Esta é a pergunta que deixamos para futuras pesquisas.

\section{BIBLIOGRAFIA}

BECKER, Howard. Métodos de pesquisa em ciências sociais. São Paulo: Hucitec, 1997.

BECKER, Howard. Outsiders: estudos de sociologia do desvio. Rio de Janeiro: Jorge Zahar, 2008.

FREIRE, Paulo. Pedagogia do oprimido. Rio de Janeiro: Paz e Terra, 2005.

GOFFMAN, Erving. Estigma: notas sobre a manipulação da identidade deteriorada.

Rio de Janeiro: LTC, 2013.

GOLDENBERG, Mirian. A arte de pesquisar: como fazer pesquisa qualitativa em ciências sociais. Rio de Janeiro: Record, 2015.

MOZ, Jane Middelton; Zawadski, Mary Lee. Bullying: estratégias de sobrevivência para crianças e adultos. Porto Alegre: Artmed, 2007.

SIBILIA, Paula. Redes ou paredes: a escola em tempos de dispersão. Rio de Janeiro:

Contraponto, 2012.

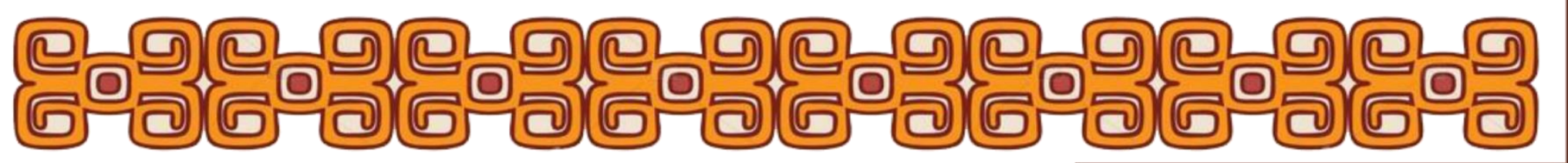

